\title{
Comparison of Self-efficacy, Test Anxiety and Competitiveness between Students of Top Private Schools and Public Schools
}

\author{
Lida Assadi Tehrani \\ Corresponding author, Department of General Psychology, Qazvin Science and Research Branch, \\ Islamic Azad University, Qazvin, Iran \\ E-Mail address:lida.assadi@yahoo.com
}

Mojtaba Amiri Majd

Department of Psychology, College of Humanities, Abhar Branch,Islamic Azad University, Abhar, Iran

Mohammad Ghamari

Department of Counseling, College of Humanities, Abhar Branch, Islamic Azad University, Abhar, Iran

\section{Doi:10.5901/mjss.2014.v5n23p2749}

\section{Abstract}

This study compared the self-efficacy, test anxiety and competitiveness in top private ${ }^{1}$ and public ${ }^{2}$ high schools students by using Ex Post FactoResearch. The sample population consisted of 338 second grade math and physics high school students (172 males and 166 females) in Tehran, who were selected through Multi-stage cluster sampling.To measure the self-efficacy, it was used, Self-efficacy questionnaire for children (Muris, 2001), to measurethe test anxiety, it was used, Test anxiety inventory (Tai, 1992) and to measure the competitiveness it was used, Winning, mastery and performance questionnaire (Franken, 1994).The results showed that general self-efficacy, test anxiety and competitiveness were higher in TPS students (emotional and academic self-efficacy were higher and there was no significant difference for social self-efficacy). Compare to boys and girls, in terms of competitiveness and self-efficacy; boys earn higher scores and in test anxiety girls had higher grades (in terms of academic and social self-efficacy, there were no significant differences between them but in emotional selfefficacy boys were at a higher level). It can be said that: both strategies and management practices were efficient in selfefficacy, test anxiety and competitiveness of students and also the students are attracted to these schools that have these features more.

Keywords: competitiveness, self-efficacy, test anxiety, High school students.

\section{Introduction}

In today's world everybody faces stress in everyday life and no one can escape from pressures of competition with others in sport, education, professional fields and other contexts,inevitably, he tries to meet the demands and requirements of modern life. In many cases due to limited resources and multitude of applicants, one is forced to compete for getting some external goals, such as winning in a competition, getting good grades in school, promoting job or putting on absolute spotlight of others. In some cases the inner motives and desiresbrought him to competition. In such an environment, the goal of the students is to show their superior capability. So instead the emphasis is on the attempt, it is on the ability and the ability and susceptibility takes the value (Feshbach \& Weiner,1991). According to Bandura (1997) self-efficacy is defined as: perceptions of students from the ability to successfully resolve the issue, learning the activities or perform them on a desire level. Studies have shown that mental health and human well-being requires an optimistic sense of self-efficacy (Maciejewski et al.,2000). A strong sense of efficacy leads to a high level of motivation, academic achievements and interests growth in educational issues (Pajares\&Schunk, 2001). Ashby \& Kathryn (2007) reported that high efficacy in talented students is related to a number of behaviors such as; enhancement of social harmony,

\footnotetext{
1 abbreviated by TPS

${ }^{2}$ abbreviated by PS
} 
improvement of interpersonal relations and social and academic skills, vice versalow efficacy in ordinary students is a major contribution to personal, social and educational problems.

Another variable studied in this research is test anxiety. Anxiety is a very common phenomenon in psychological studies, which has been researched for many years and in fact it is the most common reaction to stress (Sarason,1984). McKee (2007) showed that students in all levels of academic achievements and intellectual abilities can be affected by test anxiety. Test anxiety leads to behavioral, physical and phenomenological reactions along with the test (Zeidner, 2007). Hemberee (1988) reported that there is a negative correlation between test anxiety and success in IQ, intelligence, memory and problem solving tests. Biabangard (1999) reported that students with low level of test anxiety have better performance in difficult examsthan the easy ones, while the performance of students with moderate test anxiety is contrary; finally students with high level of test anxiety, have low function in both hard and easy exams. Since the students are the main assets of the country, especially the families, in this researchthe effort has been paid to the effect of these three factors and consequently, school administrators and education policymakers pay special attention to it. Due to the impact of training of self-efficacy promotion and its role in enhancing and improving the quality of mental and physical lather of life, its important seems great and urgent. On the other hand anxiety management training and consequentlycontrolling test anxiety by students and also having a compiled program that focus on practical solutions, to controlling and reducing it, seems necessary. Finally with regards to the positive and negative aspects of competitiveness, informing school administrators of the results of these researches will be constructive and useful.

\section{Method}

This research wasCorrelational. The sample included all male and female students who were studying in second grade mathematics and physics high schools in Tehran In the academic year 2013-2014.From twenty-two districts in Tehran three regions were selected randomly. In this study, sampling was done at 16 high schools, It includes 338 students; 177 students from TPSs (52\%) and 161 students from PSs (48\%), which were 172 male (51\%) and 166 female (49\%).

\section{Instruments}

\subsection{Test Anxiety Inventory:}

Anxiety scale has been made by Abolghasemi et al (1996). This questionnaire consists of twenty five items and grading based on Likert scale four options; never $=0$; rarely $=1$; sometimes $=2$; often $=3$. Cronbach's alpha was for all students $\mathrm{a}=0 / 78$, male students $\mathrm{a}=0 / 75$ and female students $\mathrm{a}=0 / 79$.

\subsection{Self-efficacy Questionnaire for children and adolescents:}

This questionnaire has been made by Muris in 2001 to assess the self-efficacy of children and adolescents.this questionnaire consists of twenty three items, comprising three subtests; social (the first eight items to assess the ability to communicate with peers, decisiveness and achievingto social criteria), academic (the second eight items to assess the abilityto manage learning behaviors, mastery of curriculum and to meet the academic expectations) and emotional(the final seventh itemsto assess the ability to control and dealing with negative emotions) self- efficacy. Grading is based on Likert scale five options; $1=$ never up to 5=very much. We used Persian version this Scale. Total reliability scale was $70 \%$ and for social, academic and emotional efficacy, respectively $78 \%, 87 \%$ and $80 \%$.

\subsection{Competitiveness/Mastery Questionnaire}

This questionnaire has been made by Franken in 1995. We used Persian version this Scale, the revised 22 items Persianquestionnaire consists of 19 questions of the Franken CMQ and 3 items have been added from Franken WCMP questionnaireand grading based on Likert scale five options; $1=i t$ is never like me up to $5=$ it is completely like me. To assess the reliability and validity further researches are required.

\section{Results}

Table 1 shows, Mean, Standard Deviation andVariance Analysis (ANOVA) for three examined variables in terms of type of the school and gender. 
Table 1.The Mean,standard deviation and variance analysis ofself-efficacy, test anxiety and competitiveness.

\begin{tabular}{cccccc}
\hline variables & Type of the school & SD & Mean & Significant level & F \\
\hline \multirow{2}{*}{ Self-efficacy } & PSs & $84 \%$ & $3 / 43$ & $0 / 01$ & \multirow{2}{*}{$5 / 93$} \\
\multirow{2}{*}{ Test anxiety } & TPSs & $47 \%$ & $3 / 61$ & & \multirow{2}{*}{$0 / 35$} \\
\multirow{2}{*}{ Competitiveness } & PSs & $68 \%$ & $1 / 41$ & $0 / 00$ & \multirow{2}{*}{$18 / 78$} \\
\hline
\end{tabular}

The results in Table 1 indicate that test anxiety, competitiveness, and self-efficacy in students of TPSs are higher than PSs students. On the other hand, given that the variable self-efficacy is composed of three dimensions, to study the differences between school types and dimensions of this variable we usedanalysis of variance. The results are in the table below:

Table 2. The mean and variance analysis on the dimensions of self efficacy

\begin{tabular}{ccccc}
\hline Self-efficacy variable types & Type of the school & Mean & Significant level & F \\
\hline \multirow{2}{*}{ academic self-efficacy } & PSs & $3 / 49$ & $0 / 01$ & $9 / 81$ \\
& TPSs & $3 / 76$ & & \\
social self-efficacy & PSs & $3 / 77$ & $0 / 06$ & $3 / 43$ \\
& TPSs & $3 / 74$ & & \\
emotional self-efficacy & PSs & $3 / 04$ & $0 / 00$ & $17 / 65$ \\
\hline
\end{tabular}

The results of table 2 show that the academic and emotional self-efficacy in TPSs is superior. There is no significant difference for social self-efficacy among students of TPSs and PSs. Data from the three variables of self-efficacy, test anxiety and competitiveness according to gender as follows:

Table 3.The mean and variance analysis on efficacy, test anxiety and competitiveness according to sex

\begin{tabular}{ccccc}
\hline variables & Gender & Mean & Significant level & F \\
\hline \multirow{2}{*}{ Self-efficacy } & Female & $3 / 40$ & $0 / 00$ & $\mathbf{9 / 6 8}$ \\
& male & $3 / 64$ & & \\
Test anxiety & Female & $1 / 66$ & $0 / 02$ & $\mathbf{5 / 0 0}$ \\
\multirow{2}{*}{ Competitiveness } & male & $1 / 34$ & & $\mathbf{5}$ \\
& Female & $3 / 43$ & $0 / 01$ & \\
\hline
\end{tabular}

According to the above table there are significant differences between self- efficacy and competitiveness of female and male students. That is, the self-efficacy and competitiveness of male students are higher than female students, but the test anxiety level in female students is higher than male students.Now consider the dimensions of self- efficacy in Table 4 according to gender:

Table 4. The mean score of academic, social and emotional self-efficacy according to gender

\begin{tabular}{ccc}
\hline self-efficacy variable types & Gender & Mean \\
\hline \multirow{2}{*}{ academic self-efficacy } & Female & $3 / 65$ \\
& male & $3 / 61$ \\
social self-efficacy & Female & $3 / 70$ \\
& male & $3 / 81$ \\
emotional self-efficacy & Female & $3 / 02$ \\
& male & $3 / 37$ \\
\hline
\end{tabular}

In terms of academic and social self-efficacy, there were no significant differences between male and female students, but emotional self-efficacy of male students is higher than female students. 


\section{Discussion}

The results showed that: general self-efficacyis higher in TPS students. This study isaligned with the researches performed by Karadamas \& Azizi, 2004; Schwarzer \& Fuchs,1995; Kim, 2003 and Abedini, 2010, which reflect the relationship between self-efficacy and academic achievements.AlsoPope, 1989; Stajkovic\&Luthans, 1998 confirmed the relationship between self-efficacy and high school grades.Malpassetal (1999) have shown that emotional self-efficacy strongly affects the intensity of concern and concerns affect the academicachievements of students. Kim, 2003 believed that talented students in dealing with different situations so that they can control their environment, so it is that sense of self efficacy and personal satisfaction provided.Freeman,1983 showed that there is positive and significant relationship between self-efficacy and academic success, resulting in stress and anxiety in this group of students is reduced.According to the present research, it was concluded that the academic efficacy of TPS students is higher thanpublic schoolstudents. Haret al (2001) and Bandoraet al (1996) found that academic self-efficacy has positive relationship with positive social relationship and social performance in school. According to the present research, it was concluded that competitiveness is higher in TPS students than public school students. Daneshpajooh (1993) showed that top students believe that, academic competitions, creating competition and trying to be encouraging and further increase knowledge, speed, confidence and knowledge of how information is, and in learning the material and become familiar with exam questions has animpressiveeffect.Harackiewicset al (1997) showed that Competitive motivation has positive impact on students' scores. But Stapel \& Kooman (2005) believed that competition usually leads to conflict and cooperation to replication. Van \&Janssen(2002) found that People with high competitiveness, have little time for leisure and socializing,hence the sense of happiness reduces in them.On the other hand compettition among different communities have different meanings (Grum \& Kolence, 2008).Students from individual countries, know thecompetition,in educationalsettings more negative with no results found, but students from a collectivist society, see the competition more positive, which can leads to progress (Fulop, 2005). Important thing is; to generalize the results obtained in the West to the East should be treated with caution (Kinget al., 2012). According to the findings, it was concluded that test anxiety in TPS students are higher than public schools students.Onyeizugbo (2010) and Mohammadyari (2012) have been confirmed the negative impact of test anxiety on academic achievements. On the other hand researchers such asHolms (2001) believed that, test anxiety make people better prepare for study. But one thing that is noteworthy is that selfefficacy indicates a stronger positive association with academic achievement than test anxiety (Hattie et al., 2009 and Kadivar, 2007. According to the present study it was concluded that the efficacy of male students is higher than female students. Pintrich and DeGroot (1990)found that boys and girls have equal confidence in primary school, but in high school, boys have more. On the other hand Shyuand Hung (1999) examining relationship between academic self-efficacy and academic achievements in high school senior students concluded that there is no significant difference in academic self-efficacyof boys and girls. The results showed that competitiveness is higher among male students than female students. There have been conflicting views on competition (Ezheiet al., 1995). According to Frankenand Brown, 1992 the competitive motivations between females and males are differentandthe number of extractedfactors are more in male subjects.Sutter and Rutzler (2010) confirmed that gender differences in competitive behaviors are determined in the early years of life. Roy and Benenson (2002) found that females interfere in competitive interactions only when the resources are very few and limited whilemales are used to this kind of competition. But according to Ericsson et al., (2009) there is no significant difference between boys and girls in demands of competitive environment. The result of present study is consistent with research of Pajares\&Kranzle (2002) and Akrami (1999), which test-anxiety is higher in girls than boys. The interesting thing is that academic achievements of female students have more predictive power with test anxiety and for male students with self-efficacy (Mohammadyari, 2012). On the other hand the correlation between test anxiety and academic achievements among girls in different disciplines was significant, but in boys, it is significant only in the field of science and not in humanities and math (Shoeiry,2004). The last point that should be noted is thatmost psychological theories such as Bandura's theory represents a Western perspective and are derived from individualistic values,it isessentially to be accurately considered to use these theories in a collectivist culture, like Iran (Mortazavi, 2004). Each study has limitations and limitation of the present study were at first; a lot of questions that could lead to reduced accuracy of the subjects, second; The study was limited to three regions in Tehranand finally; lack of backgrounds connected entirely with research topic.

\section{References}

Abedini, E.(2010). "Prediction of academic achievement of high school students based on self-efficacy beliefs, socio-economic status and field of study",Moaser psychology paper, 6, (2)57-70. 
Abolghasemi, A., AsadiMoghadam, A., Najarian, B.,\&Shokrkon, H. (1996)."Build and validitate a scale to measure anxiety in high school students in Ahwaz", Journal of Psychology and Educational Science, 3,61-74.

Akrami, N. "Test Anxiety", Monthly Journal of Ministry of Education, 1999, Tabriz magazine, 3.

Ashby, J.,\& Kathryn, H. (2007)."Perfectionism and career decision making self efficacy", Journal of Employment Counseling, 44(1), 1728.

Bandora, A. (1997)."Self-Efficacy: The Exercise of contro"I. New York: Free man.

Bandora, A., Barbaranelli, C., Caprara, G. B.,\&Pastorelli, C. (1996)."Multifaceted impact of self-efficacy beliefs on academic functioning".Child Development, 67, 1206-1222.

Biabangard, E.(1999)."Anxiety Measurement and compare three methods of cognitive therapy, self training and systematic desensitization in reducing it".PhD Thesis, AllamehTabatabaii University.

Daneshpajooh, Z. (1993). "Distinctive characteristics of Top Students academic competitions and the factors affecting their academic achievements in the academic year 1991-1992", Publications office of education research council of Tehran.

Eriksson, T., Theyssier, S., \&Villeval, M, C. (2009)."Self-selection and the efficacy of tournaments".Economic Inquiry, 47, 530-548.

Ezhei, J., Dadsetan, P.,\&SadeghiGandomani,J. (1997)."Consequences of competitiveness and its relation to academic achievements in high school students", Journal of Got talent school, 24, 365-392.

Feshbach, S., \&Weiner B. (1991). "Personality", Journal of Clinical Psychology, 32,885-891.

Franken, R. E., \& Brown, D. J.(1995). "Why do people like competition? The motivation for winning, putting forth effort, improving one`s performance, performing well being instrumental, and expressing forceful/aggressive behavior", Personality and Individual Differences, 19(2), 175-184.

Franken, R. E., \& Brown, D. J. (1992). "Why do people like competition? The motivation for winning, putting forth, improving one`s performance, performing well, being instrumental and expressing forceful / aggressive behavior". Personality and Individual Differences, 21(3), 345-353.

Freeman, J. (1983). "Emotional problems of the gifted child", Journal of child psychology and psychiatry, 24, 481-485.

Fulop, M.(2005)."The development of social, economical, political identity among adolescents in the post-socialist countries of Europe". In M. Fulop, \& A. Ross (Eds.), Growing up in Europe today,11-39. U.K./Sterling, USA: TrenthamBooksStroke-on-Trent.

Grum, D. k.,\&Kolence, J.(2008)."Self-concept and competitiveness in three national cultures".Studiapsychologica, 50, $291-309$.

Har, C.W., I. D.,\& Ming, L. K. (2001).Motivational and self-regulatory process on academic and social functioning of secondary school students in Singapore.Australian association for research in education-research association, Joint international education research conference, Fremantle, Australia.http://www.aare. edu.au/01pap/cho01132.htm.

Harackiewics, J. M., Barron, K. E., Carter, S. M., Lehto, A. T.,\& Elliot A. J., (1997)."Predictors and consequences of achievement goals in the college classrooms: maintaining interest and making the grade", Journal of personality and social psychology, 73(6), 12841295.

Hattie, J. (2009). Gordon L. Bower, J. and Stephen C., "Self efficacy and academic achievement in Australian high school students: the mediating effects of academic aspirations and delinquency", Journal of adolescence, 32, 797-817.

Hemberee, G. (1988). "Correlates, Causes, Effects and Treatment of Test Anxiety", Journal of Review of Education Research, 581, 4777.

esters, C. (2001). "Protective and vulnerability factors of depression in normal adolescents", Behavior Research and Therapy, 39, 555565.

Onyeizugbo, E. U., (2010). "Self-Efficacy and Test Anxiety as correlates of Academic performance", Journal of Educational Research, $1(10), 477-480$.

Pajares, F.,\&Kranzler, J. (2002)."Self- efficacy beliefs and general mental ability in mathematical problem-solving", Emory University, University of Florida.

Pajares, F.,\&SHolms, L. (2001)."Reducing test anxiety to performance", University of South Florida, 493-115.

Hooman, H. (2002). "Multivariate data analysis in behavioral research", Parsa publications.

Kadivar, P.(2007)."Comparing Self-efficacy and Creativity in students of internet-users and non- users", Seasonal Journal of Education and Training, 89, 111-134.

Karademas, C. E.,\&Azizi, K.A,(2004). "The stress process, self- efficacy expectations and psychological health".Personality and individual differences, 43, 277-287.

Kim-Young-Ho. (2003)."Correlation of Mental health Problems with Psychological constructs in adolescence", International Journal of nursing studies, 40, 115-129.

King, R. B., Mclnereny, M.,\& Atkins, D, A. (2012)."Competitiveness is not that bad... at least in the East: Testing the hierarchical model of achievement motivation in the Asian setting". International Journal of Intercultural Relations, 36, 446-457.

Maciejewski, P. K.(2000). Prigerson H. G. and Mazure C. M," Self efficacy as amediator between stressful life events and depressive symptoms", The British Journal of Psychology, 176, 373-378.

Malpass, J. R., Neil, H. F.,\&Hocevar, D. (1999)."Self-regulation, goal orientations, self-efficacy, worry and high-stakes math achievement for mathematically gifted high school students". Report Review, 21(4), 281-283.

McKee, T. (2007)."Test anxiety and the impact on student's exam performance", Retrieved may6from: http://www.education.csm.edu/students/tmckee/scholary_paper.htm.

Mohammadyari, G. (2012). "Comparative study of relationship between General perceived Self-efficacy and Test anxiety with Academic Achievement of Male and Female Students", Procedia - Social and Behavioral Sciences, 69, 2119-2123. 
Mortazavi, S. (2004). "Interrelationship between efficiency concept and perceived support from family, teachers and friends in samples of high school students in Tehran"Research Journal of Educational innovations,3(8),13-38.

Muris, P., Schmidt, H., Lambrichs, R. \&Mechunk, D. H.(2001)."Self beliefs and school success: Self-efficacy, Self-concept, and school achievement in R. Riding and Rayner", (Eds.).Perception. London: Alben Publishing.

Pintrich, P. R., \&DeGroot, E. V.(1990)."Motivational and Self- regulated Learning Components of Classroom Academic Performance", Journal of Educational Psychology, 82(1), 33-40.

Pope, W. (1989)."Self efficacy enhancement with children and adolescents". New York: Pergamon Press.

Roy, R., \&Benenson, J. F. (2002). "sex and contextual effects on children`s use of interference competition", Developmental Psychology, 38, 306-312.

Sarason, I. G. (1984)."Stress, anxiety and cognitive interference: Reaction to test", Journal of personality and social Psychology,46, 929938.

Schwarzer, R.,\& Fuchs, R.(1995). "Changing risk behaviors and adopting health behaviors: The role of self-efficacy beliefs". In A. Bandura, (Ed.).Self-efficacy in changing societies. New York: Cambridge University Press,259-288.

Shoeiry, M., Molamirzaii, M., Parvari, M., Shahmoradi, F.,\&Hashemi, A. (2004)."Study of test anxiety and academic achievement with regard to gender and field of study in high school students", Bimonthly scientific-research journal of shahed university, eleventh year, new series, 6, 55-62.

Shyu, H.,\&Hung, L. (1999)."The relation of academic self- efficacy to academic outcomes for senior high school students", Journal of Education and Psychology, 22(2), 267.

Stajkovic, A.,\&Luthans, F. (1998). "Self-efficacy and work related performance: A meta-analysis",PsychologicalBulletin, 124, $240-261$.

Stapel, D. A.,\&Kooman, W. (2005). "Competition, cooperation and the effects of others on me", Journal of Personality and Social Psychology, 88(6), 1029-1038.

Sutter, M., Rutzler, D. (2010). "Gender differences in competition emerge early in life". IZADiscussion paperNo. 5015, Institute for the study of labor, Bonn.

Van de Vliert, E.,\&Janssen, O. (2002)."Better than "Performance motives as roots of satisfaction across more and less developed countries", Journal of Cross-cultural psychology, 33(4), 380-397.

Zeidner, M. (2007)."Test anxiety in educational contexts: Concepts, findings, and future directions", In P. A. Schutz\& R. Pekrun(Eds.). Emotion in education, Boston: Elsevier Academic Press,pp.165-184. 